\title{
Analysis of the CSI300 Index Futures' Influence on the Volatility of the Spot Market
}

\author{
Zhao Zhenyu \\ Economics, Shanghai University \\ Shanghai, China \\ Zhyzhao1999@126.com
}

\author{
Geng Yan \\ Economics, Shanghai University \\ Shanghai, China \\ gengyan1209@163.com
}

\begin{abstract}
The successful launch of CSI 300 stock index futures on the market improve China's capital market, the operating efficiency of the market and provide investors a risk management tool which can hedge and arbitrage. The existing time of CSI 300 stock index futures is short, so the existing research is based on emulation trading for the study. This paper will use GARCH, TARCH model to describe the question in three parts: first, the review of CSI300 index futures emulation trading. Second, establish the GARCH model and compare the difference of volatility on the spot due to the launch of CSI 300 stock index futures; third, "leverage effect" of the influence is verified by TARCH model. The results show that due to the introduction of CSI300 stock index futures, volatility of stock spot return can be reduced, the persistence for market to absorb old information is enhanced; CSI300 index futures influencing the spot market of the price volatility have the ability of negative symmetry which means that bad news has a stronger infect than good news to yield volatility.
\end{abstract}

Keywords- CSI300 index futures; volatility; GARCH model; TARCH model; symmetry

\section{INTRODUCTION}

Stock index future is based on stock price index which is specified by the Exchange. The contract of the future by both parties shows that there will be transaction in the fixed price at a specific time in the future. Stock index future is a risk management tools which can be value discovery, risk hedging, arbitrage. It is widely used by different national financial markets.CSI300 index futures began Simulation trading on October 30, 2006 and officially launched the CSI300 stock index futures on April 16, 2010. It was a significant time which changed the unilateral market situation in Chinese stock market which can do long position but be short of short position. For the relationship is close between stock index futures and spot, the research of the relationship between CSI300 stock index futures and spot makes a great meaning to the development of stock index futures, also shows some significance in the strategy of hedging and arbitrage for domestic investors.

The related researches most are empirical studies on specific markets at home and abroad.

In terms of stock index futures reduce the volatility of CSI300. Galloway and Miller (1997) believe that the S \& P 400 Index futures' launch did not significantly alter the volatility of the spot market. Chang, Cheng and Pinegar (1999) believe that the introduction of index futures increase the volatility of the spot market. Maberly, Allen and Gilbert (1989) think that the period which is selected to research is a direct relationship. Not much research scholars in domestic did related research. Zhang Lin (2010) used the method of before and after comparison and selected frequency data of simulation trading, found that after the introduction of the Shanghai and Shenzhen 300 stock index futures, the volatility of spot increased in the short term.

But after the regulatory authorities have launched related participating guidelines, the market structure has been improved significantly and the stock index futures began to play a role in stabilizing the stock market volatility.

The asymmetry of the impact the stock index futures to spot's volatility. Kan and Yoon (2007) selected stock market data in Japan, Malaysia, Singapore, Taiwan, as the object of study, and used GARCH, GJR-GARCH, APGARCH model for data regression analysis. They indicated that a lot of speculation may exacerbate the volatility asymmetric further. Zhang Yan (2011) study shows that there is a significant asymmetry, that bad news will be more intense. Similarly, Cheng Zhuo (2012) concluded that the volatility of the SH300 index futures was not significantly affected to spot market, but improves the efficiency of market information transmission.

After the official launch of the domestic stock index futures the related research is less. Some articles did not make the analysis the positive and negative impact about the asymmetry of stock index futures to the spot. In this paper, through qualitative and quantitative analysis, using the latest data and the improved TARCH and GARCH models and introducing a dummy variable changes on behalf of the change before and after the launch of HS 300 stock index futures, we have the conclusion about the existence, directional and asymmetric of CSI300 stock index futures' impact on the spot.

\section{EMPIRICAL ANALYSIS}

\section{A. Data Selection and Processing}

Official trading of CSI300 index futures began on April 16, 2010, the paper select the price of active contracts which is more representative of the market performance as observation target, while select CSI300 index closing price as comparative data. Selected samples in Table1 are from Bloomberg database.

In this paper, the method of logarithm yields will be used in data processing, the formula is as follows: 


$$
r=\log \left(p_{t}\right)-\log \left(p_{t-1}\right)
$$

Where, $\mathrm{r}$ represents daily yield, $p_{t} 、 p_{t-1}$ represents the t,t-1 day's closing price.

TABLE I. SAMPLE INTRODUCTION

\begin{tabular}{|l|c|c|}
\hline & Period & No. \\
\hline Full Sample & Jan.4,2007-Dec.31,2012 & 1462 \\
\hline $\begin{array}{l}\text { Subsample before futures } \\
\text { (Sample 1) }\end{array}$ & Jan.4,2007-Apr.15,2010 & 800 \\
\hline $\begin{array}{l}\text { Subsample after futures } \\
\text { (Sample 2) }\end{array}$ & Apr.15,2010- Dec.31,2012 & 662 \\
\hline
\end{tabular}

In this paper, the method of Logarithm yields will be used in data processing, the formula is as follows:

$$
r=\log \left(p_{t}\right)-\log \left(p_{t-1}\right)
$$

Where, $\mathrm{r}$ represents daily yield, $p_{t} 、 p_{t-1}$ represents the t,t-1 day's closing price.

\section{B. Qualitative Analysis}

To illustrate the impact on the stock price after the launch of CSI 300 index futures, we first look at the correlation coefficient in Table 2, reaching 0.999018. This preliminary instructs the intimate relationship between the spot market return and future market return.

Then in Table 3, 0.024638>0.014121, it indicates that after the introduction of futures, CSI 300 Index yields volatility on spot market declined.

Above analysis shows that the introduction of the CSI 300 index futures impact on the spot volatility. The need further detailed analyze.

TABLE II. CORRELATION COEFFICIENT BETWEEN CSI300 SPOTS AND FUTURES

\begin{tabular}{|c|c|c|}
\hline & Spot & Futures \\
\hline Spot & 1.000000 & 0.999018 \\
\hline Futures & 0.999018 & 1.000000 \\
\hline
\end{tabular}

TABLE III. CSI300 RETURN STANDARD DEVIATION BEFORE \& AFTER THE LAUNCH OF CSI300 FUTURES

\begin{tabular}{|l|r|}
\hline & \multicolumn{1}{|c|}{ Standard Deviation } \\
\hline Before & 0.024638 \\
\hline After & 0.014121 \\
\hline
\end{tabular}

\section{C. $\quad$ Model Building}

\section{1) Data Description Analysis}

As shown in Table 4, the basic descriptive analysis to the samples was going, in all samples, skewness $<0$, kurtosis $>3$, show obvious characteristics of sharp peak and heavy tail, and are not suitable for normal distribution to describe their distribution. CSI 300 stock yields variance exist significant agglomeration as in Fig .1-4. So we use $\mathrm{ARCH}$ model to describe the returns series.

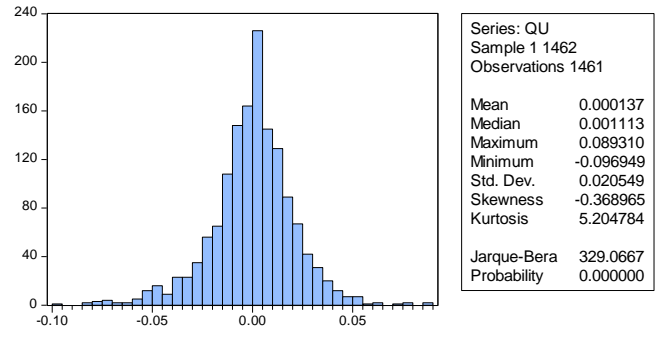

Figure 1. CSI300 Yield data statistics

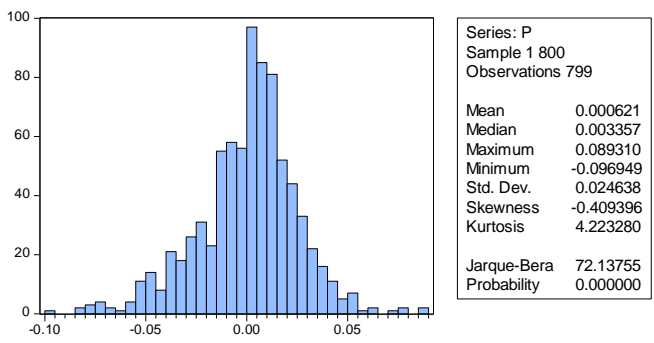

Figure2 CSI300 Yield data statistics(Before CSI300 future launch)

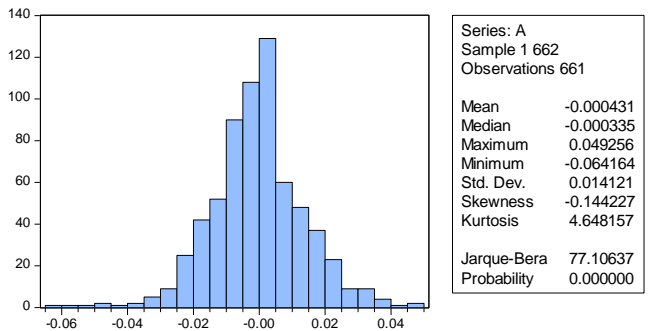

Figure3 CSI300 Yield data statistics(Before CSI300 future launch)

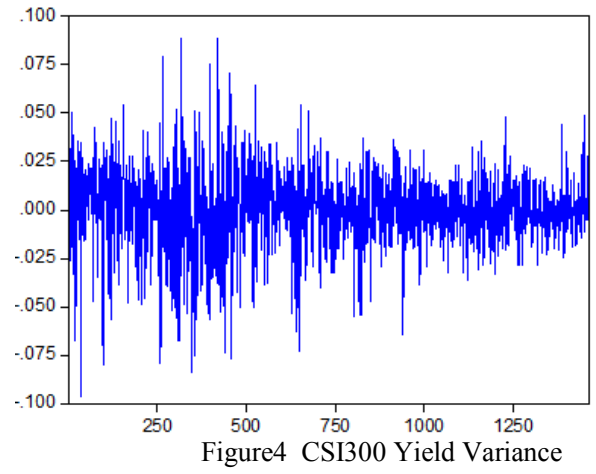

TABLE IV. DESCRIPTIVE ANALYSIS ON OBSERVATIONS

\begin{tabular}{|l|l|l|l|}
\hline & Mean & Median & Maximum \\
\hline Full Sample & 0.0001 & 0.0011 & 0.0893 \\
\hline $\begin{array}{l}\text { Sample1(Before } \\
\text { Futures Launch) }\end{array}$ & 0.0006 & 0.0034 & 0.0893 \\
\hline $\begin{array}{l}\text { Sample2(After } \\
\text { Futures Launch) }\end{array}$ & -0.0004 & -0.0003 & 0.0493 \\
\hline
\end{tabular}

\begin{tabular}{|c|c|c|c|c|}
\hline & $\begin{array}{l}\text { Minimu } \\
\mathrm{m}\end{array}$ & $\begin{array}{l}\text { Standard } \\
\text { Deviwaion }\end{array}$ & Skewness & $\begin{array}{l}\text { Kurtosi } \\
\text { s }\end{array}$ \\
\hline Full Sample & -0.0969 & 0.0205 & -0.3690 & 5.2048 \\
\hline $\begin{array}{l}\text { Sample1(Before } \\
\text { Futures Launch) }\end{array}$ & -0.0969 & 0.0246 & -0.4094 & 4.2233 \\
\hline $\begin{array}{l}\text { Sample2(After } \\
\text { Futures Launch) }\end{array}$ & -0.0642 & 0.0141 & -0.1442 & 4.6482 \\
\hline
\end{tabular}

Continue: 


\section{2) GARCH Model Building and Results Analysis}

After the stability test and ARCH-LM test (Table5,6) on sample data, we build AR (1) -GARCH $(1,1)$ model.

$\alpha_{0}$ represents the uncertainty of the system itself, $\alpha_{1}$ represents the impact to market of new information, $\beta$ represents the continuing effects of the information, specific formula following: ( where $\alpha_{0}>0, \alpha_{1}>0, \beta>0, \alpha_{1}+\beta<1$ )

$$
\begin{aligned}
& R_{t}=\theta R_{t-1}+\varepsilon_{t} \\
& h_{t}=\alpha_{0}+\alpha_{1} \varepsilon_{t}^{2}+\beta h_{t-1}
\end{aligned}
$$

TABLE V. STABILITY TEST RESUlT

\begin{tabular}{|l|l|l|}
\hline & ADF Test & P Value \\
\hline Full Sample & -37.61562 & 0.0000 \\
\hline Sample 1 & -27.59676 & 0.0000 \\
\hline Sample 2 & -26.44409 & 0.0000 \\
\hline
\end{tabular}

TABLE VI. ARCH-LM TEST ON FULL SAMPLE

\begin{tabular}{|l|l|l|}
\hline & Value & P Value \\
\hline F- statistical & 2.087982 & 0.0420 \\
\hline$R^{2}$ & 14.48945 & 0.0431 \\
\hline
\end{tabular}

Then, we get two GARCH models to fit the spot market, the result shows in Table 7,8:

Before the launching of CSI300 index futures:

$h_{t}=(4.96 \mathrm{e}-06)+0.061 \varepsilon_{t}^{2}+0.93 h_{t-1}$

After the launching of CSI300 index futures:

$h_{t}=(6.13 \mathrm{e}-06)+0.022 \varepsilon_{t}^{2}+0.95 h_{t-1}$

Results analysis: Equation (5) (6) in contrast, $4.96 \mathrm{e}-06<6.13 \mathrm{e}-06$, indicates that after the launch of CSI 300 index futures, the system itself uncertainties enhanced; $0.061>0.022$, indicates that the impact of new information to market weakening after the launch of CSI 300 index futures, $0.93<0.95$, the persistence of the information effect had been enhanced after the launch of CSI 300 index futures.

TABLE VII.GARCH(1,1) ESTIMATED RESUltS OF SAMPLE 1

\begin{tabular}{|l|l|l|l|}
\hline & Coefficient & Variance & P Value \\
\hline Constant & $4.96 \mathrm{E}-06$ & $3.08 \mathrm{E}-06$ & 0.1074 \\
\hline $\begin{array}{l}\text { Squared } \\
\text { residuals }\end{array}$ & 0.061275 & 0.011971 & 0.0000 \\
\hline GARCH term & 0.930918 & 0.012413 & 0.0000 \\
\hline
\end{tabular}

\begin{tabular}{|c|c|c|c|}
\hline & Coefficient & Variance & P Value \\
\hline Constant & $6.14 \mathrm{E}-06$ & $4.11 \mathrm{E}-06$ & 0.1356 \\
\hline $\begin{array}{l}\text { Squared } \\
\text { residuals }\end{array}$ & 0.022007 & 0.010087 & 0.0291 \\
\hline $\begin{array}{r}\text { GAR } \\
\text { CH term }\end{array}$ & $\begin{array}{ll} & 0.94631 \\
3 & \\
\end{array}$ & $128^{0.028}$ & $00^{0.00}$ \\
\hline
\end{tabular}

TABLE VIII. GARCH(1,1) ESTIMATED RESUltS OF SAMPLE 2

Reason analysis: First, the enhancing systemic risk does not meet our expectation. In theory stock index futures should be able to reduce the uncertainty of the spot. It may be caused for the sake of imperfect and young

futures market. Also, although $\alpha_{0}$ the coefficient varies in size, but in itself is extremely too small to impact actually. Secondly, after the futures launch the impact of new information on the spot price volatility becomes weaker. It is the value discovering and risk averse of the futures that make the market parties to have the right anticipation under the regime of public bidding transaction and auction trading system. Third, after the CSI 300 index futures launch, the spot index is more rational to absorb information with continuity

About the above analysis, the two situations before and after the CSI 300 index futures launch can merge into GARCH $(1,1)$ with a dummy variable $\mathrm{D}, 0,1$ respectively represent before and after the introduction of stock index futures as follows.

$$
\begin{aligned}
& \text { Models: } \\
& R_{t}=\theta R_{t-1}+\varepsilon_{t} \\
& h_{t}=\alpha_{0}+\alpha_{1} \varepsilon_{t}^{2}+\beta h_{t-1}+\lambda D
\end{aligned}
$$

Result:

$$
h_{t}=8.13 e-06+0.035 \varepsilon_{t}^{2}+0.95 h_{t-1}-(4.75 e-06) D
$$

(9)

3) Excluding market factors to restudy the impact of the CSI 300 index futures on the spot

The return volatility of CSI300 index is weaker after the launch of corresponding futures. We need further study the reason of this change to spell whether it's own function or the macro factors Because after April 15, 2010, the CSI300 stock index futures introduction, China and the world economy is not stable, such as our country's economic crisis and the four trillion economic stimulus plan, the European debt crisis and global inflation and unemployment confusion. These macroeconomic factors from the outside are likely to have an impact on yield volatility.

In order to study the impact of CSI300 stock index futures trading or other unexpected factors on the spot market factors volatility we need to select a control variable to describe the market profile. CSI 300 index components cover Shanghai and Shenzhen, so the control variables we selected must be able to effectively reflect the overall operation of the Shanghai and Shenzhen stock market. At the same time there would be not too much overlap, otherwise we can't study other factors besides market. So, we chose SMEs CSI 500 index which can reflect the overall situation in Shanghai and Shenzhen.

As can be seen from Table 9, the correlation coefficient between CSI 300 Index and the CSI 500 Index yields reached 0.9 highly, which shows that it is macro market factors that make the CSI 300 Index volatility to a large extent.

TABLE IX. COEFFICIENT BETWEEN CSI 300 AND THE CSI 500

\begin{tabular}{|l|l|l|}
\hline & CSI300 & CSI500 \\
\hline CSI300 & 1.000000 & 0.914511 \\
\hline CSI500 & 0.914511 & 1.000000 \\
\hline
\end{tabular}

The control variable, which reflects market factors, CSI 500 index return series was introduced to the original GARCH model. Through the stationary test of CSI 500 
Index and analyzing autocorrelation and partial correlation coefficients to build models:

$$
\begin{aligned}
& R_{300 t}=\phi R_{500 t}+\theta R_{300 t-1}+\varepsilon_{t} \\
& h_{t}=\alpha_{0}+\alpha_{1} \varepsilon_{t}^{2}+\beta h_{t-1}
\end{aligned}
$$

The results show in Table10,11

TABLE X. GARCH(1,1) (EXCLUDING MARKET FACTORS)ESTIMATED RESULTS OF SAMPLE 1

\begin{tabular}{|l|l|l|l|}
\hline & Coefficient & Variance & P Value \\
\hline Constant & $1.20 \mathrm{E}-05$ & $8.45 \mathrm{E}-06$ & 0.1563 \\
\hline $\begin{array}{l}\text { Squared } \\
\text { residuals }\end{array}$ & 0.04897 & 0.029466 & 0.0965 \\
\hline GARCH term & 0.816036 & 0.12036 & 0.0000 \\
\hline
\end{tabular}

TABLE XI. GARCH(1,1) (EXCLUDING MARKET FACTORS)ESTIMATED RESULTS OF SAMPLE 2

\begin{tabular}{|l|l|l|l|}
\hline Constant & Coefficient & Variance & P Value \\
\hline $\begin{array}{l}\text { Squared } \\
\text { residuals }\end{array}$ & $2.07 \mathrm{E}-06$ & $6.10 \mathrm{E}-07$ & 0.0007 \\
\hline GARCH term & 0.082135 & 0.018513 & 0.0000 \\
\hline Constant & 0.855046 & 0.030216 & 0.0000 \\
\hline
\end{tabular}

Compare two coefficients and draw conclusions under the condition of excluding the macroeconomic factors. Ignore the minimal impact of constant changes. First,0.048970<0.082136, indicating that after the introduction of CSI300 stock index futures trading the spot market have a stronger return volatility to new information than before. And the conclusion is inconsistent with before; Secondly, $0.816036<0.855046$, after the CSI 300 index futures launch, the spot index is more rational to absorb information with continuity. This is consistent with before.

The inconsistence is for two possible reasons. First, after excluding off macroeconomic factors, the conclusions situation exists. Second, the CSI 500 Index does not represent the condition of macroeconomic factors totally, while including its own non-system factors.

\section{4) TARCH -Model Building}

TARCH is used to describe the leverage effect. TARCH (threshold ARCH) model proposed by Zakoian (1990) and it has the following form of conditional variance:

$h_{t}=\alpha_{0}+\sum_{i=1}^{q} \alpha_{i} \varepsilon_{t-i}^{2}+\varphi \varepsilon_{t-1}^{2} d_{t-1}+\sum_{j=1}^{p} \theta_{j} h_{t-j}$

Where $d_{t}$ is a nominal dummy variable. $\varepsilon_{t}<0$ (bad information), $d_{t=1 ;} \varepsilon_{t}>0$ good information), $d_{t}=0$. TARCH model as follow:

$$
\begin{aligned}
& R_{300 t}=\theta R_{300 t-1}+\varepsilon_{t} \\
& h_{t}=\alpha_{0}+\alpha_{1} \varepsilon_{t}^{2}+\lambda D+\gamma \mu_{t-1}^{2} d_{t-1}
\end{aligned}
$$

TABLE XII. ESTIMATED RESULTS OF TARCH MODEL

\begin{tabular}{|l|l|l|l|}
\hline & Coefficient & Variance & P Value \\
\hline Constant & $8.47 \mathrm{E}-06$ & $2.86 \mathrm{E}-06$ & 0.0031 \\
\hline Squared residuals & 0.014883 & 0.007584 & 0.0497 \\
\hline TARCH item & 0.032173 & 0.00845 & 0.0001 \\
\hline GARCH item & 0.950745 & 0.01063 & 0.0000 \\
\hline Control Variable & $-4.79 \mathrm{E}-06$ & $1.91 \mathrm{E}-06$ & 0.0121 \\
\hline
\end{tabular}

Table 12 shows: dummy variable $\lambda(-4.79 E-06)<0$, which indicates that the introduction of CSI300 index futures reduce the volatility of the spot market, although its value is very small. $\gamma(0.032173)>0$ indicate that there is an asymmetric impact between good and bad news to the spot volatility. The asymmetric is bad news has a stronger infect than good news to yield volatility.

\section{CONCLUSION AND DEFICIENCY}

\section{A. Conclusion}

By establishing TARCH GARCH model, dividing the entire sample into two samples which are the period before and after the introduction CSI 300 stock index futures, we conclude that:

- After the introduction of the return volatility of stock market is reduced while the uncertainty of CSI 300 index itself increased. The market reacted weaker to new information and the absorption of old information is continuity.

- Using improved GARCH model and introducing control variables CSI500 Index to explain macroeconomic factors, the final regression results indicate that the CSI300 return volatility is really reduced which mostly due to macroeconomic factors not the CSI300 index futures .Excluding macroeconomic factors we found that the system itself has decreased the risk of uncertainty, the introduction of futures trading makes stock market return volatility responsive to new information quickly, at the same time, the continuity of reflecting the impact of old information enhanced.

- CSI300 index futures influencing the spot market of the price volatility have the ability of negative symmetry which means that bad news has a stronger infect than good news to yield volatility.

\section{B. The Deficiency and Future Improvement}

Long-term impact on the future of CSI 300 stock index futures needs further study. More efficient models to describe the volatility of returns can be introduced in the future. In addition, the text only illustrates the effect of the CSI 300 index futures on the volatility of the spot market of return qualitatively, but doesn't use the quantitative methods to find out the causes and paths. Finally, this paper does not involve the volatility analysis in different market environments of bull and bear markets.

\section{REFERENCES}

[1] Sa R,"Option and Efficiency". Quarterly Journal of Economics 1989,90(1),pp75-89.

[2] Antoniou A. P H R P,"The Effects of Stock Index Future Trading on Stock Index Volatility:An Analysis of the Asymmetric Response of Volatility to News ". Journal of Future Market. 1998, 18,pp151-166.

[3] Geweke.J.Medeling, "the persistenes of onditional varianees: acomment" Eeonometri Reviews, 1986,5,pp1-10

[4] Ruchika Gahlota, Saroj K. Dattaa," Impact of Future Trading on Efficiency and Volatility of the Indian Stock Market: A Case of 
CNX 100 ". Journal of Transnational Management 2011,Vol.16, No. $1, \mathrm{pp} 43-57$

[5] Lawrence Harris, George Sofianos, James E. Shapiro "Programmed Trading and Intraday volatility". Review of Financial Studies, 1994,Vol. 7,No. 4,pp653-685

[6] Yakov Amihud,"Illiquidity and Stock Returns:Cross Section and Time-series Effects ".Journal of Financial Markets,2002(5)

[7] Zhuo Zheng.An Empirical Analysis of the Introduction of CSI300 Future's Influence on the Volatility of the Spot Market.[D]Shandong: Shandong University,2012
[8] Lin Zhang."The Influence of the Introduction of CSI300 Futures to the Spot Volatility-Based on the Different Periods Comparison".Changsha: Central South Univercity,2010

[9] Yu Wei.Volatility "Forecasting Models for CSI300 Index Futures “. Journal of Management Science,2010,13 (002) ,pp66-76.

[10] Tao Luo,Ying Wang."Stock Index Futures's Influence to the Volatility and Liquidity-Based on Empirical Data in China's Market". macroeconomic study ,2011 (6), pp55-77

[11] Tiemei Gao, Econometric analysis and modeling, Tsinghua University Press, 2006 